\title{
POSTGRADUATE RESEARCHERS AND THEIR RELATIONSHIP
} TO TEACHING:

\section{An Initial Exploration of Survey Findings}

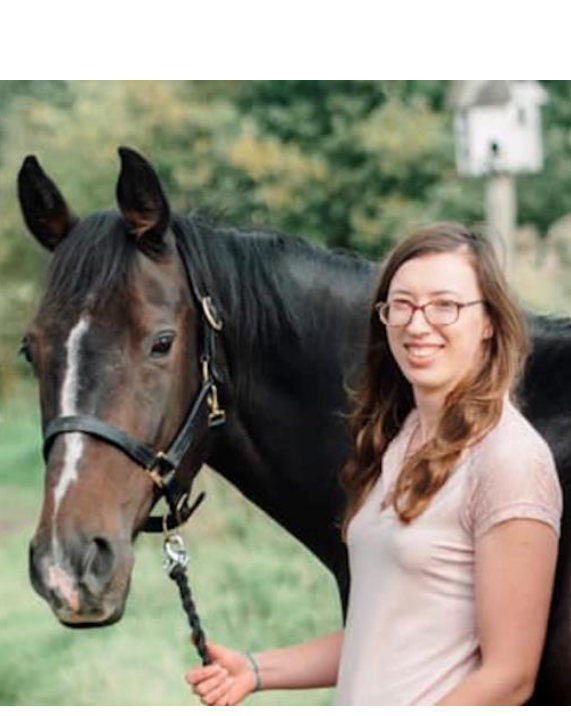

\section{Kate Lewis}

Final year PhD student in Life Sciences, University of Warwick Correspondence: k.lewis.1@warwick.ac.uk

My PhD work mostly focuses on the use of statistics to look at the role of lambs in the spread of footrot, a disease that is common in sheep flocks. I have taught in statistics-based modules in both the School of Psychology and Life Sciences, and my teaching focus is on helping to make statistics and coding with $\mathrm{R}$ accessible

\section{Abstract}

Many postgraduate researchers (PGRs) take part in teaching or have teaching-related opportunities at Warwick, but currently, little is formally documented about their experiences. The aim of this research is to find out more about PGRs and teaching at Warwick, and to provide some insight into their experiences, many of which will have been impacted by the COVID-19 pandemic. This brief overview seeks to highlight some of the initial findings from an inaugural Warwick survey of PGRs, made in relation to teaching.

Keywords: Warwick Survey, Postgraduates, Teaching Experiences, Training, COVID-19.

\section{Introduction and Methods}

PGRs at Warwick were invited to take part in an online survey about their experiences.

There were six sections to the questionnaire PGR Teacher Characteristics, Visibility of Teaching Opportunities at Warwick, Teaching Responsibilities of PGR Teachers, Awareness of Development Opportunities, Impact of Development Opportunities and Looking to the Future.

\section{Selected Results}

Response rate and distribution

The questionnaire was advertised both online and by to PGR student via departmental mailing lists in July 2021. There are 127 responses, 106 of which are useable, having been received from PGRs at Warwick who specifically gave consent for their data to be used. Of these, $45.3 \%$ are from the Faculty of Social Sciences, 33.0\% from the Sciences, Engineering and Medical departments, while 
$16.0 \%$ are from the Arts department. However, $5.7 \%$ of the respondents did not indicate their departments.

\section{How do PGRs gain teaching opportunities, and what do they teach?}

The survey was open to all PGRs at Warwick irrespective of teaching experience. Most respondents $(61.3 \%)$ indicated that they have a teaching role at Warwick. As shown in Table 1 below, PGRs mostly become aware of teaching opportunities via email or departmental advertisement, followed by word of mouth from either supervisors or friends. Some (7.5\%) PGRs are, however, not aware of any teaching opportunities in their departments.

Running seminars and marking are identified as the most common teaching roles for PGR students and this is illustrated in Table 2 below. This finding may be attributed to the fact that many respondents $(45.3 \%)$ are from various Social Science departments.

\begin{tabular}{ll}
\hline $\begin{array}{l}\text { How have you been made aware of PGR teaching } \\
\text { opportunities in your department? }\end{array}$ & $\begin{array}{l}\text { Number of } \\
\text { responses (\%) }\end{array}$ \\
\hline Email & $55(51.9)$ \\
Departmental advertisement & $28(26.4)$ \\
Word of mouth - colleagues/friends & $27(25.5)$ \\
Word of mouth - supervisor/other mentor & $25(23.6)$ \\
Not aware of PGR teaching opportunities & $8(7.5)$ \\
Warwick website: GTA job search & $0(0.0)$ \\
Other & $0(0.0)$ \\
\hline
\end{tabular}

Table 1: Awareness of Teaching Opportunities

\begin{tabular}{ll}
\hline \multicolumn{1}{c}{ Teaching participated in by PGR teachers } & \multicolumn{1}{c}{$\begin{array}{c}\text { Number of } \\
\text { responses (\%) }\end{array}$} \\
\hline Marking & $36(34.0)$ \\
Seminar - in person & $34(32.1)$ \\
Seminar - online & $31(29.2)$ \\
Individual student support sessions/mentoring - online & $19(17.9)$ \\
Laboratory (wet/dry) - in person & $17(16.0)$ \\
Individual student support sessions/mentoring - in person & $15(14.2)$ \\
Lectures - online & $8(7.5)$ \\
Lectures - in person & $8(7.5)$ \\
Other & $6(5.7)$ \\
Module convention & $2(1.9)$ \\
\hline
\end{tabular}




\section{What prevents PGRs taking teaching opportunities?}

Table 3 shows that the biggest factor which prevents PGRs from taking teaching opportunities is attributed to PhD-related time commitments. This is followed by feelings about lack of subject knowledge.

\section{Teaching-related development opportunities}

Around a third of respondents either agree or strongly agree that Warwick provides sufficient teaching-related development opportunities for PGR teachers. Table 4 shows that half of the respondents are aware of the Preparing to Teach in Higher Education course, which is a mandatory introduction course required by departments before teaching, while less than half are aware of any other courses run at Warwick, which are all voluntary.
Table 5 shows that PGRs predominantly take training courses to either improve their practice, gain experience, or boost their CV.

Table 6 suggests that PGRs would generally like more training opportunities, although a third would be potentially more likely to participate in programmes if they were paid. There was some suggestion that peer-support programmes would be wellreceived. However, Table 7 demonstrates that awareness of available courses is currently relatively low. This invariably means that lack of awareness of the training courses on offer is potentially the bigger problem, rather than lack of opportunities at Warwick.

\begin{tabular}{ll}
$\begin{array}{l}\text { What does, or might prevent you from taking } \\
\text { teaching opportunities? }\end{array}$ & $\begin{array}{l}\text { Number of } \\
\text { responses (\%) }\end{array}$ \\
\hline Time commitments - PhD related & $53(50.0)$ \\
Feelings of lack of subject knowledge & $35(33.0)$ \\
Unaware of opportunities & $20(18.9)$ \\
Other & $17(16.0)$ \\
Time commitments - non-PhD related & $14(13.2)$ \\
Lack of supervisor approval & $11(10.4)$ \\
Rejection via application & $8(7.5)$ \\
\hline
\end{tabular}

Table 3: Inhibitive Factors to Teaching for PGRs

\begin{tabular}{ll}
\hline Which of the following courses are you aware of? & $\begin{array}{c}\text { Number of } \\
\text { responses (\%) }\end{array}$ \\
\hline Preparing to Teach in Higher Education & $53(50.0)$ \\
APP PGR (Academic and Professional Pathway for Postgraduate Researchers who Teach) & $38(35.8)$ \\
PGA TLHE (Postgraduate Award in Teaching and Learning in Higher Education) & $22(20.8)$ \\
TPiHE (Teaching Practice in Higher Education) & $6(5.7)$ \\
Departmental courses/training & $29(27.4)$ \\
Academic Development Program & $18(17.0)$ \\
Other & $3(2.8)$ \\
\hline
\end{tabular}




\begin{tabular}{ll}
\hline $\begin{array}{l}\text { Reasons for undertaking teaching related } \\
\text { development opportunities? }\end{array}$ & $\begin{array}{l}\text { Number of } \\
\text { responses (\%) }\end{array}$ \\
\hline To improve practice or gain experience & $33(31.1)$ \\
To boost CV & $24(22.6)$ \\
Course recommended by supervisor/mentor & $13(12.0)$ \\
Other - please state & $4(3.8)$ \\
\hline
\end{tabular}

Table 5: Reasons for Undertaking Training Opportunities

\begin{tabular}{ll}
\hline How can support for PGR teachers be improved? & $\begin{array}{l}\text { Number of } \\
\text { responses (\%) }\end{array}$ \\
\hline Payment for undertaking training & $32(30.2)$ \\
Mentoring/peer support & $27(25.5)$ \\
Mandatory requirements for departments to provide & $24(22.6)$ \\
mentorship/support to new tutors & \\
Further training or Continuous Professional & $24(22.6)$ \\
Development & \\
Spaces for sharing practice/experience & $21(19.8)$ \\
Networking & $15(14.2)$ \\
Socialising & $12(11.3)$ \\
Other & $1(0.9)$
\end{tabular}

Table 6: Measures for Improving PGR Teacher Support

\begin{tabular}{ll}
$\begin{array}{l}\text { If you have not undertaken teaching related development opportunities, } \\
\text { why is this? }\end{array}$ & $\begin{array}{l}\text { Number of } \\
\text { responses (\%) }\end{array}$ \\
\hline Unaware of these opportunities & $28(26.4)$ \\
They are unpaid & $12(11.3)$ \\
Lack of time & $11(10.4)$ \\
Courses were not recommended as useful by supervisor/other mentor & $5(4.7)$ \\
Courses were discouraged by supervisor/other mentor & $0(0.0)$ \\
Other - please state & $0(0.0)$
\end{tabular}




\section{Conclusions}

Many PGRs at Warwick are involved in teaching in some way and this study provides some of the first insights into how PGRs acquire teaching opportunities at Warwick, their teaching roles, and their awareness of various developmental opportunities available to them. Initial findings suggest that opportunities to teach are largely departmentally-driven, perhaps through some informal networks.

The study also highlights that, potentially, a lack of awareness of the opportunities available is a barrier to PGRs undertaking teaching-related development opportunities, and that although PGRs identify that they would like more opportunities, awareness of the ones currently available is seemingly low. The question of how to raise awareness, equitably, of the opportunities currently available to the PGR community, is one that needs to be addressed.

There appears to be an appetite, overall, for more PGR teacher support, and for this support to include mentoring or peer support. An interesting initiative that can propel this need into action is the buddy and peer mentoring scheme launched by the newly launched Warwick Postgraduate Teaching Community. This novel project aims to connect PGR teachers from a distance, whilst also creating an enabling digital environment for PGR teachers to share insightful pedagogic practices.

The full results from the PGR Teaching Survey will be published in the Autumn 2021.

To cite this article: Kate Lewis, 2021. “Postgraduate Researchers and their Relationship to Teaching: An Initial Exploration of Survey Findings". Journal of PGR Pedagogic Practice, 1, xx-xx. Available at: [url] 